\title{
PREVALENCE AND DETERMINANTS OF USE OF MODERN HEALTH FACILITIES FOR DELIVERY BY NIGERIAN WOMEN
}

\author{
Gbolahan A. Oni ${ }^{1}$, Fasina F Fagbeminiyi ${ }^{2 \star}$ \\ ${ }^{1}$ Department of Demography and Social Statistics, Covenant University, \\ Ota, Ogun State, Nigeria, Gbolahan.oni@covenantuniversity.edu.ng \\ ${ }^{2}$ Department of Demography and Social Statistics, Covenant University, \\ Ota, Ogun State, Nigeria, niyi.fasina@covenantuniversity.edu.ng
}

${ }^{*}$ Corresponding Author

\begin{abstract}
Delivery is potentially a hazardous process as most maternal mortality occurs during delivery. Utilization of maternal health services offered by institutional or modern health facilities is known to be associated with decrease in maternal, neonatal and infant mortality rates because health facility delivery affords the woman the attendance of skilled or professional health personnel at childbirth.

Yet many women in the developing countries including Nigeria still deliver outside health facilities, particularly at home without professional attendance, risking survival of both the mother and the baby. Nigeria is one of the countries of the world that have the highest maternal, infant and child mortality rates. It is also one of the countries with low use of health facilities for delivery. In 1999 , only $37.3 \%$ of mothers in the country delivered in health facilities (NDHS, 1999), and in 2003 only $32.6 \%$ delivered in health facilities (NDHS 2003). Identifying the factors affecting the use of modern health facilities for delivery is essential for appropriate policies and programs that can help to increase health facility utilization for delivery and thereby decrease maternal and infant mortality in Nigeria. This study aimed to establish the prevalence (i.e., levels) of use of modern health facilities (public and private), for delivery in Nigeria. It also aimed at identifying the socioeconomic and demographic determinants of use of health facility delivery in the country. The study was a cross sectional analyses of the data from the Nigeria Demographic and Health Survey (NDHS) conducted in 2008. The NDHS covers a nationally representative sample of more than 36,000 households based on 2006 Population and Housing Census of the Federal Republic of Nigeria, 2006. The NDHS interviewed 33,385 women aged 15 to 49 years, and 15,486 men aged 15 to 59 years. This study analysed responses from the 17,635 women aged 15-49, who had at least one live birth in the five years preceding the survey. The univariate, bivariate and multivariate analytical techniques were adopted. To estimate the effects of socioeconomic and demographic factors on delivery in health facilities, binary logistic regression analysis was adopted as the multivariate technique. Results show that only $36.7 \%$ of deliveries took place in health facilities. Using binary logistic regression analysis, the following variables were significant predictors of use of health facilities for delivery: mother's age, children ever born, education, region of residence, religion and wealth status. In order to significantly increase the level of use of health facilities for delivery by Nigerian women, and thereby reduce maternal and infant mortality, policies and programs should be well targeted to those identified groups with low utilization of health facilities
\end{abstract}

Keywords: Determinants, Maternal Mortality, Healthcare Facilities Delivery, Nigeria 


\section{INTRODUCTION}

One of the public health problems affecting a great proportion of the population of developing countries is maternal death (WHO, 2005). About 600,000 women aged 15-49 years die yearly due to pregnancy related complications (Population Reference Bureau, 2002; 2012; Addai, 1998, World Health Organization, 2012). Maternal mortality is described as the death of a woman during pregnancy or within 42 days after delivery, excluding accidental causes of death (Lindroos \& Luukkainen, 2004; World Health Organisation (WHO), 2007). Worldwide, there has been a significant drop in the number of women dying from pregnancy and childbirth. However, Africa still lags behind other parts of the world in making childbirth safe and the conditions in sub-Saharan Africa remain at emergency levels. In the 1990s, while the maternal death rate was as high as 1,100 per 100,000 live births in Nigeria, 600 in India, about 400 in Kenya, it was only 10, 12 and 17 for Italy, Poland and US respectively (World Bank Group, 2014). By the year 2010, while appreciable reduction has been achieved in other countries, Nigeria still ranks high among the countries with high maternal mortality due to low utilization of modern healthcare facilities (WHO, 2008).

Many women in the developing countries including Nigeria still deliver outside health facilities, particularly at home without professional attendance, risking survival of both the mother and the baby when complications arise. The use of modern healthcare services in developing countries have tended to demonstrate that people's acceptance or rejection of modern healthcare facilities is based on their perception of its effectiveness (Erasmus, 1961, Addai, 2000) and on how well it mesh with their traditional beliefs and practices concerning health and illness (Paul, Foste, 1976)

In Nigeria, the choice to deliver outside modern healthcare infrastructure settings could be motivated by varying factors such as economic, social, physical, cultural or institutional. Outside the modern healthcare infrastructures setting, expectant mothers may be assisted by an traditional birth attendant (TBA) who may be skilled or unskilled.

An essential aspect of preserving health is to identify the factors that enable or prevent people from making healthy choices in either their life-style or their use of medical care and treatment, the underlying assumption being that behaviour is best understood in terms of an individual's perception of their social environment (Tipping and Segall, 1995). This study therefore tries to establish the prevalence (i.e., levels) of use of modern health facilities (public and private), for delivery in Nigeria. It also aimed at identifying the socioeconomic and demographic determinants of use of health facility for delivery by women in the country. This will enable policies and programs to be properly targeted to those identified groups with low utilization of health facilities for delivery in order to significantly increase the level of use of health facilities for delivery by Nigerian women, and reduce maternal and infant mortality in Nigeria.

\section{METHODS}

The study was a cross sectional analyses of the data from the Nigeria Demographic and Health Survey (NDHS) conducted in 2008. The NDHS covers a nationally representative sample of more than 36,000 households based on 2006 Population and Housing Census of the Federal Republic of Nigeria, 2006. The NDHS interviewed 33,385 women aged 15 to 49 years, and 15,486 men aged 15 to 59 years. The study used quantitative data from the 2008 Nigeria Demographic and Health Surveys (NDHS). In all, a total sample of 33,385 women aged 15-49 years and 15,486 men aged 15-59 were interviewed using a structured questionnaire. For the purpose of this study, a sub-sample of 17,635 (weighted) population consisting women aged 15-49 years whose recent delivery occurred in the five years preceding the survey was utilized based on the focus of the study. This study analysed responses from the 17,635 women aged 15-49, who had at least one live birth in the five years preceding the survey. The univariate, bivariate and multivariate analytical techniques were adopted. To estimate the effects of socioeconomic and demographic factors on delivery in health facilities, binary logistic regression analysis was adopted as the multivariate technique.

\section{RESULTS}

Table 1 provides the estimates of the prevalence (i.e., levels) of use of healthcare facilities for delivery by various categories of the six demographic and socioeconomic factors considered in this paper. It also provides the bivariate association of these factors with delivery in health facilities. The overall level of use by women in the country was $36.7 \%$. Mother's age was significantly associated with prevalence of use (Chisquare $=227.2$ on 4 d.f; $P<0.001$ ). Use increases with age of the mother except that mothers who were 35 years or older were having less use of health facilities for delivery than were mothers aged 25-34 years old. Level of use was lowest for mothers less than 20 years old (23.3\%) and highest for mothers aged 30-34 years $(42.5 \%)$. Also the level of use decreases with increase in children ever born (Chi-square $=441.2$ on 3 d.f; $\mathrm{P}<0.001)$. Level of use was highest among those women having their first child $(42.7 \%)$ and lowest 
among women having their $7^{\text {th }}$ or higher order birth $(20 \%)$. There was significant regional variation in the level of use of health facility for delivery, with women from the northern part of the country having much lower level of use than women from southern parts of the country ((Chi-square $=5015.3$ on 5 d.f; $P<0.001)$. The lowest use occurred in North West region (9.4\%) and highest level of use occurred in South East Region $(74.3 \%)$.Level of use of health facility for delivery significantly increased with increase wealth index status of the women, with $7.8 \%$ use among women in the poorest wealth index and $80.4 \%$ use among those in the richest wealth index (Chi-square $=5306.7$ on 4 d.f; $\mathrm{P}<0.001$ ). Also, level of use significantly increased with women's education (Chi-square $=5383.8$ on 3 d.f; $P<0.001$ ). The level of use among women with no education was $10.7 \%$ while the level of use among mothers who had tertiary education was $90.2 \%$. Finally, Christian women had significantly higher use of health facility for delivery (57.3\%) than their Islamic counterparts $(20.6 \%)$, (Chi-square $=2492.7$ on 1 d.f; $P<0.001)$.

\begin{tabular}{|c|c|c|c|c|}
\hline Variables & $\begin{array}{l}\text { Delivery in a Health } \\
\text { Facility }\end{array}$ & $\begin{array}{l}\text { Did not deliver in a } \\
\text { Health Facility }\end{array}$ & $\begin{array}{l}\text { Chi-Square } \\
\text { Value }\end{array}$ & P-Value \\
\hline Age Group & $(\mathrm{N}) \quad(\%)$ & $(\mathrm{N}) \quad(\%)$ & & \\
\hline Less Than 20 & $(23.28)$ & $(76.72)$ & & \\
\hline $20-24$ & $(30.33)$ & (69.67) & & \\
\hline $25-29$ & $(40.27)$ & (59.73) & & \\
\hline $30-34$ & $(42.45)$ & $(57.55)$ & & \\
\hline $35+$ & $(36.55)$ & $(63.45)$ & 227.2052 & 0.000 \\
\hline \multicolumn{5}{|c|}{ Children Ever Born } \\
\hline 1 Child & $(42.66)$ & $(57.34)$ & & \\
\hline 2-3 Children & (37.36) & $(62.64)$ & & \\
\hline 4-6 Children & $(31.30)$ & $(68.70)$ & & \\
\hline 7+ Children & $(20.00)$ & $(80.00)$ & 441.2077 & 0.000 \\
\hline \multicolumn{5}{|l|}{ Region } \\
\hline North central & (42.63) & $(57.37)$ & & \\
\hline North east & (13.94) & $(86.06)$ & & \\
\hline North west & $(09.43)$ & $(90.57)$ & & \\
\hline South east & $(74.34)$ & $(25.66)$ & & \\
\hline South west & (70.63) & $(29.37)$ & & \\
\hline South south & $(49.00)$ & $(51.00)$ & 5015.2651 & 0.000 \\
\hline \multicolumn{5}{|l|}{ Wealth Index } \\
\hline Poorest & $(7.76)$ & (92.24) & & \\
\hline Poorer & (16.51) & (83.49) & & \\
\hline Middle & $(34.50)$ & $(65.50)$ & & \\
\hline Richer & $(57.69)$ & $(42.31)$ & & \\
\hline Richest & $(80.37)$ & $(19.63)$ & 5306.654 & 0.000 \\
\hline \multicolumn{5}{|c|}{ Educational Level } \\
\hline No education & $(10.68)$ & (89.32) & & \\
\hline Primary & $(40.46)$ & $(59.54)$ & & \\
\hline Secondary & $(66.41)$ & (33.59) & & \\
\hline Higher & $(90.15)$ & $(09.85)$ & 5383.7832 & 0.000 \\
\hline \multicolumn{5}{|l|}{ Religion } \\
\hline Christianity & $(57.26)$ & $(42.74)$ & & \\
\hline Islam & (20.62) & $(79.38)$ & 2492.7448 & 0.000 \\
\hline
\end{tabular}

Source: Computed by the Researcher from 2008 NDHS (2017) 
To establish the socioeconomic and demographic determinants of use of health facility, the binary logistic regression analysis was carried out and the results are as provided in Table 2. All the six variables indicated significant effects on the use of health facility for delivery. For example, the likelihood that a woman will use health facility increases with her. Women who were 35 years and older were $67 \%$ more likely to deliver in a health facility than women who were less than 20 years of age $(O R=1.67 ; P<0.001)$ The likelihood of use decreased with the number of children ever born. Women who were having their seventh or higher order birth were about $48 \%$ less likely to deliver in a health facility compared to women having their first birth $(\mathrm{OR}=$ 0.542; $\mathrm{P}, 0.001$ ). There was significant variation between regions on use of health facilities for delivery. Compared to North Central state, women in South East and South West were significantly more likely to deliver in health facility $(\mathrm{OR}=1.53$ and 1.35 respectively, $\mathrm{P}<0.001)$. However, women in North East, North West and South South were less likely to deliver in health facility when compared to women in North Central $(\mathrm{OR}=0.436,0.21$ and 0.475 respectively, $\mathrm{P}<0.001)$. Women who had tertiary level education were more than eight times more likely to deliver in health facility than were women without any education $(\mathrm{OR}=8.4 ; \mathrm{P}$ $<0.001$ ). Women in the richest wealth index status were about 11 times more likely to deliver in health facility than were women in the poorest category of wealth index $(\mathrm{OR}=11.2 ; \mathrm{P}<0.001)$. Finally, women who were Muslims were about $15 \%$ less likely to deliver in health facility than were Christian women $(\mathrm{OR}=0.86$; $\mathrm{P}=0.007$ ). The Likelihood Ratio $(\mathrm{LR})$ test for the fitted model indicated a very good fit (Chi-Square $=7860$ on 20 d.f, $P<0.001$ ).

Table 2: Binary Logistic Regression Analysis Results for Determinants of Health Facility Delivery by Nigerian Women

\begin{tabular}{|c|c|c|c|c|}
\hline Variables & Odds Ratio(OR) & P- Value & Standard Error & $\begin{array}{c}95 \% \text { Confidence } \\
\text { Interval }\end{array}$ \\
\hline \multicolumn{5}{|l|}{ Current Age } \\
\hline Less than 20 & R.C & & & \\
\hline $20-24$ & 1.005 & 0.961 & 0.101 & $(0.825,1.234)$ \\
\hline $25-29$ & 1.263 & 0.025 & 0.132 & $(1.030,1.50)$ \\
\hline $30-34$ & 1.496 & 0.000 & 0.170 & $(1.197,1.868)$ \\
\hline $35+$ & 1.670 & 0.000 & 0.198 & $(1.324,2.108)$ \\
\hline \multicolumn{5}{|c|}{ Children Ever Born } \\
\hline 1 Child & R.C & & & \\
\hline 2-3 Children & 0.742 & 0.000 & 0.051 & $(0.650,0.849)$ \\
\hline 4-6 Children & 0.622 & 0.000 & 0.049 & $(0.532,0.726)$ \\
\hline 7+ Children & 0.542 & 0.000 & 0.054 & $(0.446,0.659)$ \\
\hline \multicolumn{5}{|l|}{ Region } \\
\hline North central & R.C & & & \\
\hline North east & 0.436 & 0.000 & 0.030 & $(0.382,0.499)$ \\
\hline North west & 0.210 & 0.000 & 0.016 & $(0.182,0.244)$ \\
\hline South east & 1.528 & 0.000 & 0.121 & $(1.308,1.786)$ \\
\hline South west & 1.353 & 0.000 & 0.094 & $(1.181,1.551)$ \\
\hline South south & 0.475 & 0.000 & 0.033 & $(0.414,0.544)$ \\
\hline \multicolumn{5}{|c|}{$\begin{array}{l}\text { Highest } \\
\text { Educational Level }\end{array}$} \\
\hline No education & R.C & & & \\
\hline Primary & 2. 032 & 0.000 & 0.118 & $(1.813,2.277)$ \\
\hline Secondary & 3.493 & 0.000 & 0.227 & $(3.076,3.966)$ \\
\hline Tertiary & 8.399 & 0.000 & 1.066 & $(6.549,10.772)$ \\
\hline \multicolumn{5}{|l|}{ Wealth Index } \\
\hline Poorest & R.C & & & \\
\hline Poorer & 1.796 & 0.000 & 0.133 & $(1.552,2.077)$ \\
\hline Middle & 3.115 & 0.000 & 0.226 & $(2.703,3.590)$ \\
\hline Richer & 5.965 & 0.000 & 0.450 & $(5.144,6.916)$ \\
\hline Richest & 11.176 & 0.000 & 0.995 & $(9.387,13.306)$ \\
\hline
\end{tabular}


IJASOS- International E-Journal of Advances in Social Sciences, Vol. III, Issue 8, August 2017

\begin{tabular}{|l|l|l|l|l|}
\hline Religion & & & & \\
\hline Christianity & R.C & & & \\
\hline Islam & 0.858 & 0.007 & 0.048 & $(0.769,0.958)$ \\
\hline
\end{tabular}

Source: Computed by the Researcher from 2008 NDHS (2017)

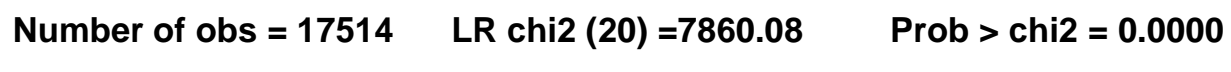

Log likelihood $=-\mathbf{7 1 7 8 . 6 5 0 2} \quad$ Pseudo R2 $=0.3538$

\section{CONCLUSION}

The study found that the use of health facility for delivery in Nigeria is very low (36.6\%). It also found that women's age, education, children ever born, wealth index and religion were important predictors of use health facility for delivery by Nigerian women. It found that there was great variation in the use of health facilities among the various regions in the country, with women in the southern part of Nigeria delivering more in health facilities than were their counterparts in the northern part. Women of young ages (24 years and under), high parity ( 4 and above), no education, poor wealth index status, and Muslims, were least likely to deliver in health facilities. Therefore, in order to significantly increase the level of use of health facilities for delivery by Nigerian women, policies and programs that are well targeted to these identified groups must be given serious consideration. For example an aggressive campaign to encourage women in the three northern regions of the country and also in the South South region, particularly in the poor and rural communities of those regions, may result in significant enhancement of the use of health facilities for delivery in Nigeria which can then result in the reduction of maternal and infant mortality in Nigeria.

\section{REFERENCE LIST}

Addai I. (1998). Demographic and socio-cultural factors influencing use of maternal health services in Ghana. African Journal of Reproductive Health 2(1):73-80.

Addai, I. (2000). Determinants of use of maternal-child health services in rural Ghana. Journal of Biosocial Science 32(1):1-15.

Erasmus C. (1961).Man takes control: cultural development and American aid. Minneapolis, Minn, USA: University of Minnesota Press.

Lindroos Anna \&LuukkainenAnnu-Riikka (2004).Antenatal care and maternal mortality in Nigeria. Public Health Program-exchange to Nigeria. July, 2004.

Nigerian Demographic and Health Survey (2008).Calverton, Maryland: National Population Commission (NPC) Nigeria and ORC Macro, 2008, 1-5.

Population Reference Bureau. Making motherhood safer (2002): overcoming obstacles on the pathway to care. Washington, DC: Population Reference Bureau

Tipping, G., Segall, M. (1995). Healthcare Seeking Behaviour in Developing Countries: An Annotated Bibliography and Literature Review.

World Bank Group (2014). Maternal Mortality Ratio, Modelled Estimate per 100,000 live births. World Bank Group, 2014.http://data.worldbank.org/indicator/SH.STA.MMRT

WHO, (2005).Mortality database table, Geneva: WHO; 2007

WHO. Annual Report 2007, Department of Making Pregnancy Safer. WHO, 2008, Geneva/Switzerland

World Health Organization (2008), Factsheet, Maternal Mortality, Department of Making Pregnancy Safer.

World Health Organization (2012). Trends in maternal mortality: 1990 to 2010 (WHO, UNICEF, UNFPA and The World Bank estimates).World Health Organization, Geneva, Switzerland. 2012. ISBN: 978924 1503631. 